\title{
Floresta, política e trabalho: a exploração das madeiras-de-lei no Recôncavo da Guanabara (1760-1820)
}

\author{
Forest, politics and labor: the extraction of timber
} in the Recôncavo da Guanabara (1760-1820)

\author{
Diogo de Carvalho Cabral*
}

\section{RESUMO}

$\mathrm{O}$ artigo procura contribuir para o adensamento da historiografia acerca das operações de extração das madeiras-delei, espécies de árvores particularmente propícias à construção naval e por isso legalmente reservadas à apropriação preferencial por parte da Coroa portuguesa no território colonial. $\mathrm{O}$ recorte espaço-temporal abarca os sertões do Recôncavo da Guanabara (Capitania do Rio de Janeiro) e, em particular, a bacia do rio Macacu no final do período colonial. Usa-se documentação variada (crônicas oficiais, descrições de viajantes, correspondência, lista nominativa de habitantes e inventário post-mortem) com o objetivo de mostrar que as relações socioeconômicas dos atores envolvidos (funcionários reais, proprietários fundiários, fabricantes, serradores etc.) entre si e com a floresta eram ditadas por negociações cotidianas que viabilizavam a 'letra fria' das leis metropolitanas. Palavras-chave: exploração madeireira; indústria de construção naval; Rio de Janeiro colonial tardio.

\section{ABSTRACT}

The article aims to contribute for the still rarified historiography about the extraction of madeiras-de-lei, those tree species that are particularly suitable for shipbuilding and, for that reason, legally reserved for preferential appropriation by the Portuguese crown in the Brazilian colonial territory. The space-temporal outline embraces the inner lands of Recôncavo da Guanabara (Rio de Janeiro captaincy), in particular the Macacu river basin, at the end of the colonial period. Varied documentation (official chronicles, travelers accounts, letters, a economic-demographic census, and a post-mortem inventory) is used in order to show that socioeconomic relations among the actors involved (royal bureaucracy, landowners, timber producers, sawyers, etc.), and those between them and the forest were dictated by daily life negotiations which made the 'cold letter' of metropolitan laws viable.

Keywords: timber exploitation; shipbuilding industry; late-colonial Rio de Janeiro.

\footnotetext{
${ }^{\star}$ Doutorando em Geografia (PPGG/UFRJ) - Núcleo de Pesquisas em Geografia Histórica, Departamento de Geografia - Instituto de Geociências/CCMN - Universidade Federal do Rio de Janeiro (UFRJ), Rua do Senado, 230/1010 - Centro. 20231-006 Rio de Janeiro - RJ - Brasil. diogocabral@superig.com.br.
} 
Com a expansão da indústria naval, ${ }^{1}$ ao longo dos séculos XVI, XVII e XVIII, as árvores passaram a ser consideradas como patrimônio nacional e usadas também como instrumento de manobra de política externa. As potências européias buscariam então, a partir de um arsenal de políticas intervencionistas inspiradas no paradigma mercantilista, garantir o suprimento de madeira necessário à construção e mantença de frotas mercantes e de guerra. Para tanto, desenharam legislações e políticas públicas para deter a depleção de seus estoques florestais, inclusive - e, talvez, principalmente - nos domínios ultramarinos, os quais representavam, afinal de contas, uma reabertura da fronteira de recursos ambientais. As 'madeiras coloniais', como eram conhecidas as essências florestais dos territórios conquistados nos marcos do imperialismo europeu, ${ }^{2}$ desempenharam um papel importante na conformação geopolítica da moderna economia-mundo. No caso de Portugal, cuja história de exaustão florestal começara ainda no século XII, ${ }^{3}$ o achado de uma terra na qual ao estender-se o olhar para o horizonte "não se podia ver senão arvoredos” — tal como descreveu Caminha —, apresentava-se como uma renovação súbita das reservas não só de "terra virgem”, mas também de madeira - e, conseqüentemente, também das possibilidades de manutenção e até mesmo de extensão do poderio naval.

No final do século XVIII, no contexto dos conflitos militares que prenunciaram e se seguiram à Revolução Francesa, a preocupação dos governantes portugueses com o suprimento de madeira aumentou exponencialmente. Para Balthazar da Silva Lisboa, tratava-se nada menos do que o "mais importante ramo da indústria, defesa e segurança pública”, o qual havia sido francamente desprezado pelos vice-reis de até então, "ficando exposto o grande Império do Brasil aos projetos dos infames invasores que tanto têm destruído pela pirataria a Marinha Mercantil". ${ }^{4}$ Nas duas últimas décadas da centúria, a reestruturação da gestão florestal portuguesa seria intensa, adquirindo um caráter supostamente mais científico. Aliada a essa disposição reformista, a grande demanda por recursos financeiros, acentuada por causa da catástrofe do terremoto de Lisboa, ocorrido em 1755, bem como por madeira para a reconstrução da cidade e de parte da frota lusitana, levou a uma alteração na postura do governo em relação à administração de seus estoques florestais coloniais.

A unidade organizacional básica para a extração das 'madeiras-de-lei' espécies reservadas à apropriação pela Coroa para fins de construção naval — era constituída pelas chamadas 'feitorias reais' ou 'cortes reais'. Destacava J. R. do Amaral Lapa em 1968 que essas operações eram uma instituição até 
então não estudada. De lá para cá, apenas F. W. O. Morton e S. W. Miller parecem ter se sensibilizado com a acusação dessa lacuna. ${ }^{5} \mathrm{O}$ objetivo deste trabalho é contribuir para o adensamento da historiografia acerca das operações de extração madeireira direta ou indiretamente administradas pela Coroa, enfocando os sertões da Guanabara e, em especial, a mais importante área fornecedora do Rio de Janeiro colonial tardio - a bacia do rio Macacu, localizada no nordeste do Recôncavo.

\section{OS CORTES NAVAIS NO RIO DE JANEIRO:} MECANISMOS INSTITUCIONAIS E ATORES SOCIAIS

Em primeiro lugar, é preciso fazer uma advertência conceitual de importantes implicações para a descrição que se segue, bem como para futuros estudos comparativos inter-regionais. Diga-se logo que não encontrei a expressão 'corte(s) real(ais)' nas fontes primárias com as quais trabalhei — ela foi usada nos estudos precedentes, nomeadamente os de Morton e Miller, em cujos corpos documentais aparecem, aqui e ali, os termos 'cortes reais' ou 'reais cortes.' 'Feitorias' é outro termo que também surge nas fontes referentes às capitanias nordestinas, embora com freqüência muito menor.

É bom ressaltar que este último termo parece constituir, em larga medida, uma idiossincrasia terminológica baiana, donde o encontrarmos apenas uma vez na obra de Miller, e exatamente quando se faz caso da Bahia (Miller, 2000, p.80). Mais importante que isso é sua adoção inconteste por J. R. do Amaral Lapa no clássico A Bahia e a carreira da Índia. No segundo capítulo desse texto — inteiramente dedicado às "Feitorias reais" —, Amaral Lapa define o que elas seriam. Em primeiro lugar, frisa bem que não devem ser confundidas com as feitorias de pau-brasil de tipo quinhentista: "Assim, muitos autores têm incidido em generalizações inaceitáveis, desde que não consideram os diferentes tipos de feitorias, ou pelo menos, as distinções entre a feitoria de pau-brasil nos seus objetivos, localização (simples pontos de escala) e funções e as feitorias das madeiras de construção naval..." (Lapa, 1968, p.38).

Segundo o autor, as últimas diferenciar-se-iam das feitorias de ibirapitanga em três aspectos: (1) a natureza do capital investido, (2) o padrão de distribuição espacial e (3) a mão-de-obra empregada.

Quanto ao primeiro aspecto, note-se que as feitorias de madeiras navais constituíram um genuíno fruto de iniciativas da coroa portuguesa e não chegaram a ser concedidas a agentes privados - como aconteceu com o arren- 
damento do pau de tinturaria. Caberia lembrar ainda que a negociação levada a cabo pelos gerentes das feitorias navais nunca teve como padrão o escambo ou qualquer tipo de troca direta. Pelo menos em tese - já que a crônica penúria de numerário de que sofria o Erário Régio nem sempre o permitia —, todos os pagamentos, fossem eles relativos a força de trabalho, ferramentas ou madeiras cortadas por particulares, deveriam ser feitos com dinheiro da Fazenda Real.

No que tange ao segundo aspecto, as feitorias navais tendiam a fincar lona num sítio nas proximidades das matas a serem exploradas, quando não se embrenhavam nelas. Procurava-se, além disso, o estabelecimento à margem dos rios, excelentes vias para o rápido escoamento do produto.

Finalmente, no que toca à mão-de-obra, prevaleceu a remuneração tanto daquelas funções para as quais o conhecimento técnico e/ou empírico era mister - como a marcação das árvores, o corte, a arrumação das toras e o transporte - quanto do trabalho propriamente braçal, muito embora por vezes se utilizassem escravos. Os postos de direção eram entregues a mestres carpinteiros vindos do Reino. Para a supervisão geral de todos os funcionários empregados na feitoria, nomeava-se um administrador, ao qual cabia a gerência de toda a região madeireira compreendida na exploração ligada à construção naval.

Segundo F. W. O. Morton — que trabalhou com um recorte espaço-temporal apenas um pouco menos amplo que Amaral Lapa, mas utilizou um corpus documental bastante diferente —, os 'cortes reais' "podem ser vistos como uma variante do familiar padrão de governo colonial brasileiro no qual a Coroa, em troca de lucros e recrutas, legitimava o controle e a exploração do campo pelas elites locais". Para Miller, um 'corte real' era simplesmente "uma operação de madeiramento administrada pela Coroa” ( a royally administered timbering operation). Acredito que tenha sido com base nesta definição que ele efetuou o teste empírico de sua tese, segundo a qual as operações madeireiras régias nunca se estabeleceram firmemente no Rio de Janeiro (Morton, 1978, p.46; Miller, 2000, p.38, 86).

Devo destacar que os termos que aparecem na documentação que analisei são 'cortes' ou 'cortes de madeiras' — sem o genitivo 'real' ou qualquer outro que possa designar a idéia de 'relativo à Coroa'. Pois bem: o que seriam, então, estes 'cortes'? Na capitania do Rio de Janeiro, os cortes eram operações sistêmicas, mas não-sistemáticas, de derrubada, falquejo e transporte de madeira naval. Elas eram sustentadas por recursos públicos administrados por um oficial militar subordinado, até 1798, ao Provedor-mor da Fazenda e, de- 
pois disso, ao intendente geral da Marinha. É fundamental que dois pontos específicos dessa definição sejam esmiuçados, por se tratar dos pilares da organização madeireira estatal no Rio: a falta de sistematicidade e a administração dos recursos financeiros.

Quando digo que os cortes fluminenses não eram sistemáticos, quero dizer que não havia um aparato burocrático in loco com o objetivo de fornecer madeira continuamente. Não é que a demanda por esse material tivesse um caráter esporádico, afinal os arsenais da Marinha e do Exército sofriam constantemente com sua escassez. Refiro-me, antes, ao fato de que a mobilização das pessoas e dos instrumentos de trabalho para a extração das árvores próprias para a construção naval só ocorria a partir de uma ordem superior do provedor ou, mais tarde, do intendente da Marinha. Ao que parece, comparados aos seus congêneres nordestinos, os cortes fluminenses estavam muito mais embasados sobre uma rede informal de cumplicidade e favorecimentos, donde prescindiam de mecanismos formal-administrativos mais rigorosos e 'transparentes' - o que ajudaria, até mesmo, a explicar a falta de documentação.

No que toca à questão da administração dos recursos financeiros, os cortes fluminenses não se encaixavam inteiramente na definição de Amaral Lapa, aproximando-se mais daquela proposta por Morton. No Rio, instaurouse um regime no qual se delegava a responsabilidade sobre todos os procedimentos madeireiros até o porto fluvial de embarque a um importante fazendeiro local que também tivesse algum posto militar, em geral o de comandante do terço de ordenanças do distrito. No final do Setecentos, esses administradores dos cortes deveriam, em tese, ser nomeados pelo Conselho do Almirantado, que os recrutaria dentre os componentes do Corpo da Marinha Real; sua jurisdição e seu soldo seriam análogos aos administradores dos pinhais de Leiria (Lapa, 1968, p.40). Na prática, contudo, assim como no caso do sul da Bahia, estudado por Morton, esses administradores não ganhavam um salário, mas recebiam dinheiro da Provedoria Real (algumas vezes em adiantamento) para cobrir os custos da compra de ferramentas (foices, machados, serras etc.) e do pagamento da mão-de-obra empregada nas derrubadas, falquejo e transporte terrestre por todo o período necessário à produção prescrita pela Coroa. Liberadas essas quantias em dinheiro, as forças estatais só voltavam a se mobilizar para buscar as peças de madeira já prontas nas docas fluviais. Em suma: diferentemente dos cortes paraibanos, pernambucanos e alagoanos - e, em menor grau, talvez, dos baianos - , nos quais havia toda uma estrutura burocrática de gerenciamento direto da área ma- 
deireira (composta, além dos administradores, de inspetores, escrivães, almoxarifes e feitores), os cortes fluminenses eram controlados exclusivamente pelos administradores. Atacado por Pimentel de Noronha quando da onda regulatória dos 'Planos', no período 1799-1800, esse sistema foi defendido por José Caetano de Lima, como se pode comprovar pelo seu discurso ao vice-rei Conde de Rezende:

Ill.mo e Ex.mo Senhor, o meu parecer he, q. V.Ex.a emcarregue a pessoas de quem faça mais confidencia, os cortes das Madeiras, pagando-se toda a despeza pelo que for justo, athe o Porto de Embarque, hindo o Bergantim de Sua Alteza Real buscalas, para se evitar o frete ... Respeito a despeza de falquejo, Serrarias, e transporte the o Porto de Embarque, por conta da Real Fazenda, q. pôzto isto em pratica, e constante a verdade de q. se lhes paga emediatamente, não haverá quem deixe de interessar-se no Real Serviço. (ANRJ, caixa 498, pct. 01)

A 'justiça’ das quantias pagas sem dúvida incluía uma razoável margem de lucro para os administradores. Tanto assim que havia a possibilidade de os rurícolas ligados ao administrador especializarem-se na atividade extrativista, tornando-se 'fabricantes de madeiras'. Isso se deixa entrever ainda através das queixas de Caetano de Lima acerca das irresponsabilidades administrativas de D. Luiz de Vasconcelos e Souza. Segundo o intendente, ele desorganizara o fornecimento de madeiras navais na capitania no período de seu vicereinado (1779-1790):

Constame q. deixarão de vir [madeiras] daqueles Destrictos para esta Cidade, depois q. $\sim$ se faltou com os seus devidos pagamentos as partes interessadas, no tempo q. Governou este Estado o Ill.mo e Ex.mo Antecessor de V.Ex. ${ }^{a}$, motivo este porq. os q. $\sim$ tinhão Fabricas de cortes de Madeiras, as desmancharão, e se ocuparão em fazer Engenhos de açúcar, em q. tem tirado grandes utelidades. (ANRJ, caixa 498, pct. 01)

Os mecanismos institucionais acionados nos cortes navais fluminenses podem ser bem visualizados numa carta de José Caetano de Lima datada de 1798 e possivelmente endereçada ao vice-rei. Nela, o intendente participa o que para ele era o melhor e mais rápido modo de obtenção das madeiras, que era enviar 
hûm Mestre Carpintr. ${ }^{\circ}$ inteligente e hûm official da Intendência authorizado e com dinheiro para logo as pagar: Sendo assim virão mais baratas pouco mais ou menos vinte por cento, sendo os donos obrigados apór as rreferidas Madeiras com abrevidade pocivel no Porto da Vila, $\mathrm{p}^{\mathrm{a}}$ dahy se transportar para esta Cidade.

Por outro modo indo o dito Mestre pelos dous Rios marcar todos os Paus capazes de Servir, e tomar os Números dos ditos e conhecimento de Seus donos, e depois o Official que lá Seacha em Carregado, ou outro que for ao corte das Madeiras, lhe intime ordem de V.Ex. ${ }^{\text {ca }}$ para que emediatamente os Referidos donos os mandem conduzir para esta Cidade, e venhão receber o seu produto fazendose-lhe certo a saptisfação com dinheiro a vista.

E no cazo de não haver naqueles Rios ou Matos as Madeiras que sepercizão, e se a V.Ex. ${ }^{\text {ca }}$ lhe parecer mandar Ordem para que Seapene os Mateiros que costumão fazer Madeiras, para que Seachem nos Matos mais vezinhos adonde o Mestre detreminar, para sedar a execução as referidas madeiras, de baixo do alinhamento e medidas do Mestre, e para o bom exzeto mandar dinheiro para se pagar aos ditos Mateiros, que sendo assim me em formão que com mais pontualidade se apromptará tudo, vendo o dinheiro logo na sua mão. (ANRJ, caixa 498, pct. 01, grifo meu)

Caso não fossem encontradas, nesses rincões, as madeiras adequadas para o falquejo de "Espaldõens, Mãos de Sinta, e Caximbos", deveria ir o mestre carpinteiro às matas da Posse de modo a "fazer corte nas Madeiras de Paroba, levando gente para o dito corte". Para se fazer "esta de Ligencia com mais brevidade", seria de grande adianto "Levar Portaria de V.Ex. ${ }^{\text {ca }}$ para em virtude dela lhe darem os moradores da queles Lugares, todo o auxilio necessario" (ANRJ, caixa 498 , pct. 01 ).

As madeiras cortadas de árvores enraizadas em terras particulares deviam ser pagas, ou seja, a propriedade privada das madeiras era reconhecida; elas tinham donos que deviam ser recompensados com uma quantia em dinheiro, senão no próprio momento da retirada da madeira - o que agilizava enormemente o processo ao estimular a cooperação dos proprietários - , pelo menos de forma não-parcelada quando da visita do produtor ao arsenal. Dean fala sobre a necessidade dessas viagens dos madeireiros à capital - e dos constrangimentos delas derivados -, embora seu motivo, segundo ele, fosse a requisição de uma licença para o corte das 'madeiras-de-lei'. ${ }^{6}$ Apesar da semelhança formal, esses dois tipos de procedimento parecem-me muito diferentes do ponto de vista institucional. Ir até a sede do poder estatal pedir autorização 
para apropriar-se de um bem que jaz em terras suas configura-se como o reconhecimento de que aquele bem não é seu, mas fazer o mesmo para receber um valor monetário que lhe é devido significa exatamente o contrário.

A recomendação de se carregar uma 'portaria' indica que os proprietários das florestas podiam criar — e é muito provável que freqüentemente criassem - muitos problemas aos oficiais da Coroa encarregados dos cortes. Sem documento do vice-rei e - o que era muito mais importante — sem dinheiro, a possibilidade de os capatazes do arsenal voltarem 'de mãos abanando’ era grande. É de se imaginar que se tenha chegado a esse estado de coisas por meio de um ajustamento e aprendizado históricos relativamente longos e que muito deveram à situação da capitania fluminense como uma porção do espaço colonial onde o direito florestal sempre foi muito mais modelado pelo jogo dos interesses privados do que pela letra da legislação metropolitana.

\section{OPERAÇÕES DE EXTRAÇÃO NA BACIA DO MACACU}

Ao longo de toda a segunda metade do século XVIII os cortes das madeiras navais no Recôncavo da Guanabara eram, sem sombra de dúvida, os mais importantes da capitania do Rio de Janeiro. O distrito de Campos dos Goitacazes, no norte fluminense, também foi uma importante fonte de madeiras para a construção naval, embora não se tenha notícias mais pormenorizadas sobre a organização dos cortes por aquelas bandas. Temos duas evidências para meados da centúria. Por aviso do secretário de Estado Diogo da Mota Corte Real, de 27 de julho de 1754, encomendaram-se, pela Provedoria da Fazenda Real, muitas dúzias de tapinhoã para os tonéis da aguada da Marinha Real. Em 1760, pelo secretário de Estado Francisco Xavier de Mendonça Furtado, mandou-se encaminhar para o Arsenal de Lisboa 9 mil aduelas para trezentos tonéis e, para os reparos das fortalezas e fortes do Maranhão, 1.500 pranchões de vinhático e quatrocentos paus para eixos. Todas essas madeiras foram cortadas nos Campos dos Goitacazes, onde abundavam e havia toda a facilidade de exportação e condução por água até os portos de embarque. As 860 dúzias de tabuados produzidas pelo distrito em 1778 não incluíam "Tapinhoans, nem Parobas por que destas, só vão as quantidades que mandão as receitas da Fazenda Real'?

As referências às madeiras navais de Campos diminuem sensivelmente no último quartel do século XVIII, o que pode muito bem significar uma real diminuição do estoque florestal e, conseqüentemente, das remessas. A des- 
peito disso, há indicações de que a riqueza vegetal da região ainda fosse bastante grande. Em 1785, um carregamento de pau-brasil em direção ao Arsenal Real de Lisboa contabilizava 12 toras provenientes do distrito campista, a segunda maior contribuição, atrás apenas do distrito de Guaratiba — uma posição facilmente explicável pela presença da Fazenda de Santa Cruz (AHU, Seção de Avulsos, caixa 135, doc. 42, n.3). Mais de trinta anos depois, Aires de Casal ainda apontava a existência de três qualidades de ibirapitanga na área de Campos. ${ }^{8}$

De todo modo, concorria sensivelmente contra a viabilidade dos cortes nessa região a distância em relação ao porto carioca - muito maior do que aquela que separava as matas do Recôncavo do mesmo porto e que, com efeito, aumentava à medida que o desmatamento empurrava a franja florestal para o interior das planícies aluviais - e a natureza do transporte aquático que tinha de ser empreendido: a navegação de cabotagem não deixava de ser uma navegação oceânica, sujeita, portanto, a dificuldades consideravelmente maiores do que aquela praticada pelas vias fluviais e dentro das águas protegidas da Baía de Guanabara. Isto favorecia sobremaneira os cortes do Recôncavo, onde a bacia do Macacu possuía posição predominante.

Visto isso, avancemos para a descrição dos dois cortes existentes na bacia: o da 'Pope' (ou Posse), localizado na freguesia de Itaboraí, e o da 'Papocaya' ou 'Collegio', na freguesia de Santo Antônio de Sá. As duas lavras florestais distavam 60 quilômetros uma da outra (ANRJ, caixa 498, pct. 01).

Estabelecido desde o final de 1798, o corte da Posse objetivava tão-somente a extração das perobas, "as quaes se achão unicamente naquella mata, e em outras que ficão mais pelo interior do Sertão” (ANRJ, códice 67, v.26, fl.71). A exploração e o armazenamento dessas "preciozas Madeiras", contudo, fazia-se de modo muito descuidado: as toras ficavam "expostas a tanto tempo ao rigor do sol e chuvas, e algumas já metidas em xarcos d'agoa, a onde" deviam "necessariamente deteriorar". O panorama do corte, em meados de 1799, pode ser visualizado na Tabela 1. Quando foi vistoriado por José Caetano de Lima e Diogo Toledo de Lara Ordonhes, em julho de 1800, o corte da Posse havia enviado para os armazéns reais apenas vinte peças de madeira, e outras 43 ainda estavam sendo falquejadas dentro da mata (ANRJ, códice 67, v.26, fl.73). 


\section{Tabela 1}

Madeiras que se achavam prontas até o fim do mês de junho de 1799, no corte naval da Posse

Peças prontas para o transporte (à beira do caminho terrestre)

\begin{tabular}{lc}
\hline Tipo & Quantidade \\
\hline Primeiros braços & 16 \\
Segundos braços & 14 \\
Enchimentos & 1 \\
Curvas & 15 \\
\hline Subtotal: & 46 \\
\hline
\end{tabular}

Peças ainda dentro da floresta

\begin{tabular}{lc}
\hline Tipo & Quantidade \\
\hline Primeiros braços & 5 \\
Segundos braços & 3 \\
Terceiros braços & 1 \\
Capelos & 1 \\
Curvas & 3 \\
Paus para gasto do Arsenal & 1 \\
Sintas para gasto do Arsenal & 1 \\
\hline Total: & 61 \\
\hline
\end{tabular}

Fonte: ANRJ, caixa 498, pct. 01.

Esses cortes eram feitos nas terras pertencentes ao capitão João Coutinho Pereira, que as adquirira em 1778 com o objetivo de construir um engenho açucareiro (Lavradio, 1946, p.302). Coutinho Pereira gozava de excelente reputação junto ao intendente da Marinha, que muito se impressionou com o grande afinco com que o capitão se engajava nas atividades madeireiras régias quando inspecionou o local, em julho de 1800. Assim se expressou o intendente ao relatar suas observações ao ministro D. Rodrigo de Souza Coutinho: 
Não me posso dispençar de fazer ciente a V.Ex.a das boas qualidades que encontrei no Capitão de Milicias ... João Coutinho Pereira, no Citio da Posse, e se todos os Senhores de Engenho se entereçassem com tanto zelo e actividade no Real Serviço não haveria tantas dificuldades em aparecerem Juntas de Bois para puxarem os paos ao Porto de Embarque, este Capitão está sempre prompto com os seus Bois e Escravos gratuitamente para puxarem os paos que estão promptos dentro do Mato, para o Caminho de Carro, vindo alguns da Serra, e de bem longe, em que emprega muita gente: Tendo em sua Caza os mestres que alli se empregão, e tudo faz com m.ta satisfação e com grande dezejo de servir ao Príncipe Regente Nosso Senhor. (ANRJ, códice 67, v.26, fl.69-70)

É de se esperar que essa imensa boa vontade não fosse gratuita. Como bem mostra a mais recente historiografia colonial, o interesse em se fazer notar como um vassalo prestimoso ao rei era onipresente entre os membros da elite agrária ultramarina. Ela tinha olhos sempre gordos sobre as valiosas mercês concedidas pela Coroa, mas a obsequiosidade não era o comportamento mais comum quando se tratava especificamente do transporte das madeirasde-lei. De ordinário, verificava-se exatamente o oposto, ou seja, procurava-se fugir desses encargos, tão pesados e onerosos que eram, principalmente nas épocas de moagem da cana-de-açúcar. Interpelados por funcionários régios, os fazendeiros naturalmente mostravam-se solícitos e dispostos a conduzir "hum ou dous paos", mas sempre com a condição de que essa tarefa "comprehendesse a todos, e se fizesse com igualdade, sem excessão” (ANRJ, códice 67, v.26, fl.71). Reconhecendo a pertinência de tais reclamações, José Caetano de Lima e Diogo Toledo de Lara Ordonhes recomendam ao vice-rei a feitura de um "mappa ... onde estejão descriptos todos os Senhores de Engenho do dito Destricto" e com o qual um oficial da tropa regular possa controlar a distribuição dos encargos, fazendo que

aqueles dos ditos Snres de Engenho que ainda não tiverem feito conduzir as Madeiras, para que em dias certos mandem para o transporte dos páos, que a cada hum tocar, as juntas de bois, e carros competentes, concorrendo sempre os de dous differentes donos, no mesmo dia, para se coadjuvarem nas passagens difficeis de todo o caminho, e hirem em boa ordem, debaixo da direcção de hum soldado pago, ou de Milicias, que possa cumprir bem com o seu dever. (ANRJ, códice 67, v.26, fl.72)

Esse tipo de problema seria uma constante ao longo da década que se abria: notícias de dificuldades para persuadir os senhores de engenho a emprestar seus bois para o transporte de madeira repetem-se nos anos de 1805 e $1806 .{ }^{9}$ 
O corte da Posse era administrado pelo mestre-carpinteiro do Arsenal de Marinha, Agostinho José de Lima. Um dos primeiros mestres-carpinteiros vindos da metrópole para trabalhar na ribeira fluminense era oficial de grande habilidade e sempre gozou de grande prestígio junto às autoridades navais. Coisa da qual não gozava, contudo, era boa saúde: com idade já avançada para a época (devia contar lá seus cinqüenta e muitos anos) e dono de uma generosa silhueta, José de Lima sofria freqüentes ataques de erisipela - uma infecção epidérmica originada de lesões causadas por fungos entre os dedos dos pés (as famosas frieiras), arranhões na pele, bolhas, cortes de calos ou cutículas e coçaduras de picadas de insetos - que o impediam de permanecer muito nos matos de Itaboraí. Em razão disso, muito mais presente fazia-se um seu subordinado (cujo nome não consegui descobrir), então incumbido de fazer descer as madeiras falquejadas para a estrada e ordenar o seu transporte (ANRJ, códice 67, v.26, fl.74).

Ao longo de todo o primeiro semestre de 1799 José de Lima encontrou muitas dificuldades para a arregimentação de mão-de-obra, o que se refletia nos grandes atrasos em que incorriam os trabalhos no corte. Das oitocentas peças que constavam no planejamento inicial, apenas 61 estavam prontas ao final de junho (ver Tabela 1). Este fato envergonhava sobremaneira o velho mestre-carapina português e sem dúvida constituiu um estímulo decisivo para a visita das autoridades florestais em meados do ano seguinte. Em 2 de julho, o mestre da ribeira remeteu uma carta ao intendente naval, lamentandose profundamente do fraquíssimo desempenho conseguido até então e pedindo auxílio para a fixação dos lavradores florestais, com os quais reconhecia não conseguir estabelecer um bom relacionamento:

é gente q.e eu me não entendo con ela, largão o trabalho e auzentão-se, thé quando lhe parecem, chego a ficar alguns dias só con dous ou tres ... tenho dado parte ao Coronel q.e tem ordem de S.Ex. ${ }^{a}$ p.a me dar as providencias neceçarias, este as encarrega ao Cap.ão Mandante, o qual determinando aos Capitans das Conpanhias p.a fazerem vir estes omens, lhe respondem q.e eles se auzentão p.a partes onde se não podem descobrir, dei lhe outra Relação de dezoito omens de novo, e logo fes conq.e viessem nove, e mos mandou entregar, mandando-os eu p.a o Ranxo p.a trabalharem no outro dia, todos se auzentarão sem ficar nenhum, dei parte já desta novidade ao dito Cap.ão Mandante, ficou de ele peçoalm.te no outro dia ir, ao destrito onde eles asistem, p.a fazer conq.e eles venhão com mais brevidade: V.S. muito bem sabe q.e estes omens ganhão a seco e comem deste seu jornal, V.S. queira se lembrar deles q.e ass vendas por cá já 
não querem fiar os mantimentos, a fim de os poder animar ao trabalho... (ANRJ, caixa 498 , pct. 01 )

Com o dinheiro ganho nos cortes, esses trabalhadores compravam nas vendas e tavernas locais tudo o que precisavam para o uso e sustento diário seu e da sua família: alimentos, peças de roupa, pólvora, chumbo e outros utensílios, como facas e tesouras. Embora se use aqui o termo 'jornal', o que de fato ocorria era um pagamento semanal, geralmente efetuado aos sábados, que se chamava à época de 'féria'. Era muito comum o estabelecimento de 'contas' semanais nas tavernas, prática que se baseava na confiança - tanto por parte do trabalhador como do vendeiro — no pagamento do salário pelo administrador do corte. Ao garantir o acesso aos bens necessários à sobrevivência, a instituição do crédito era um elemento essencial na criação de uma interdependência entre os vendeiros e seus clientes e, conseqüentemente, na reiteração dos laços que teciam uma rede social mais ampla abarcando os lavradores florestais, os vendeiros e a Coroa — que alimentava o sistema com liquidez. Ao não cumprir seus compromissos de empregadora, a Coroa freqüentemente corroía esses laços, o que acabava por tornar cada vez mais difícil encontrar indivíduos dispostos a correr o risco.

É muito difícil traçar o perfil social dos indivíduos empregados no corte. Não há fontes que comuniquem a composição étnica desses grupos, como aquelas que Miller (2000, p.113) usou para o estudo dos cortes paraibanos. A julgar pelo apelo recorrente à 'deserção' como demonstração de descontentamento em relação aos salários baixos e sempre atrasados, poder-se-ia supor que se tratasse de trabalhadores de origem indígena. O corte e preparo de madeiras, primeiro serviço prestado pelos indígenas à sociedade neo-européia em formação, continuaria a ser feito por eles até o século XIX, tanto no setor particular como no público. Boa parte do corte, transporte e preparo do madeiramento, da carpintaria, mastreação etc. realizados nas diversas oficinas navais repousava sobre o trabalho dos 'índios públicos' - gente escravizada em virtude do quinto régio ou concentrada nos aldeamentos. Eles tiveram um papel central, proporcionando um espaço importante para a reconfiguração das identidades indígenas ao longo de todo o período colonial. ${ }^{10}$ "Não é de admirar", argumenta Dean,

que grupos tribais que haviam sido assentados em aldeias fossem capazes de se integrar no comércio como lenhadores. Inteiramente familiarizados com o terreno, eram especializados no reconhecimento das espécies de árvore e estavam dispos- 
tos a trabalhar em tarefas ocasionais e sem supervisão. Tornavam-se também serradores; na verdade, especializavam-se nesta arte. (Dean, 1996, p.180-181)

Neste sentido, não surpreende o fato de que se tenham acirrado os conflitos entre os setores madeireiros estatal e privado pela utilização da força de trabalho barata e qualificada dos índios após a expulsão dos jesuítas da colônia brasileira, em 1759 (Miller, 2000, p.109-110).

Outro indício que reforça a hipótese de que os trabalhadores dos cortes navais eram indígenas destribalizados é o relato do mestre carpinteiro de que os tais empregados freqüentemente refugiavam-se em 'outro distrito'. Embora a sede da vila de São José d'El-Rei, um antigo aldeamento jesuítico, fosse mais próxima do centro nervoso do ecúmeno neo-europeu (na freguesia de Itambi), parece que os cerca de 430 aldeados (contados em 1797, Discripção..., AHU, Avulsos, Caixa 165, doc. $n^{\circ}$ 62, cap.9 $)^{11}$ gozavam ainda do direito a terras nos sertões do rio Guapiaçu: o relatório do mestre de campo Alexandre Álvares Duarte e Azevedo assinala uma sesmaria de uma légua por meia (18 $\mathrm{km}^{2}$ ) "pertencente aos Indios" naqueles rincões, terras que ainda se achavam por ser cultivadas (Lavradio, 1946, p.294). Por força, essas áreas incultas não eram utilizadas livremente pelos aldeados, nem muito menos em seu benefício; há relatos de práticas de extorsão de força de trabalho envolvendo a exploração de madeira. Em 1779, o capitão-mor João Baptista da Costa encaminhou à rainha Dona Maria I um detalhado relatório contendo graves denúncias contra o desembargador Manoel Francisco da Veiga e o diretor da aldeia, Feliciano Joaquim de Souza. Eles eram acusados de obrigar os aldeados a roubar madeira em matas alheias. Segundo o denunciante, cada índio produzia dez feixes de lenha por dia, os quais eram vendidos na cidade, ficando o dinheiro com o diretor do aldeamento. ${ }^{12} \mathrm{~A}$ acusação parece ter se mostrado procedente, pois Souza foi destituído do cargo, sendo substituído naquele mesmo ano por um seu antigo subordinado, Leonel Antonio de Almeida (Discripção..., AHU, Avulsos, Caixa 165, doc. nº 62, cap.9).

Porém, não devemos idealizar o papel da cultura indígena na caracterização desses trabalhadores florestais. Grande parte da herança nativa foi exterminada com os seus possuidores antes que pudesse ser transmitida, e o conhecimento ainda disponível se perpetuava com muita dificuldade. Com o tempo, as reduções missionárias perderam sua identidade e se fundiram com o restante dos assentamentos mestiços pauperizados. Os quase dois séculos e meio transcorridos desde os primeiros contatos interétnicos haviam produzido um largo contingente de mamelucos pobres que viviam de pequenos tra- 
balhos florestais, instrumentalizando fragmentos de 'saberes tradicionais' no contexto abrangente de uma moderna economia de troca. Grande parte da etnonímia usada pelos atores de então incorporava o reconhecimento dessas articulações sociais; 'caipira', por exemplo, um termo tupi pejorativo, significava, segundo Dean, "lenhador da floresta" (Dean, 1996, p.119).

Da raiz da serra desciam as madeiras já falquejadas até o local de embarque, situado um pouco abaixo do Porto das Caixas, percorrendo a exorbitante distância de 27 quilômetros de 'caminho de carro'. ${ }^{13} \mathrm{O}$ capitão João Coutinho e o mestre José de Lima empenhavam-se para atalhar o itinerário. Seu plano era abrir um novo caminho - cuja feitura demandaria o trabalho de oito pessoas ao longo de meio dia - que passaria por umas matas virgens pertencentes ao próprio João Coutinho e por uma parte das capoeiras de Manoel Vieira Vitela e dos herdeiros de Manoel Gomes da Silva, levando diretamente ao rio Mutuapira, com o que se diminuiria a distância a ser vencida em mais de três quilômetros. Além disso, planejava-se a construção de quatro ou seis carretões calçados de ferro - que precisaria ser enviado ao mestre José de Lima — para a condução das madeiras (ANRJ, códice 67, v.26, fls.72 e 74).

O carregamento era recebido no porto de embarque pelo tenente-coronel de milícias José da Costa Barreiros, seu proprietário. Como os portos eram privados - porque as terras doadas como sesmarias incluíam os corpos d'água —, os oficiais militares possuidores de docas fluviais eram naturalmente privilegiados na conformação do itinerário das madeiras régias; faziam também muito freqüentemente o papel de negociantes, comprando a madeira dos cortadores locais e vendendo-as na cidade. A toponímia local guarda, até hoje, resquícios desse processo de comercialização, presentes em denominações como 'Porto Tabuado'.

O acúmulo de águas e sedimentos nas porções mais baixas da paisagem - um problema onipresente na história das relações homem-meio na Baixada Fluminense - tendia a se agravar com o aumento da retirada da cobertura florestal, na medida em que esta elevava o aporte de matéria orgânica na vazão dos rios. A navegação pelo rio das Caixas e pelo rio Caceribu encontrava-se freqüentemente embaraçada pela presença de grande quantidade de lodo e galhada grossa (ANRJ, códice 67, v.26, fl.74).

Outra dificuldade para o transporte fluvial das madeiras era a densidade da mata ciliar, que atrapalhava a atracação das embarcações nas margens dos rios. Caetano de Lima e Diogo Ordonhes contam que "o Mestre do Barco q. alli foi tomar os vinte paos [acima referidos], achou o Rio das Caixas emba- 
raçado de Arvores por hûa parte das suas margens, que difficultão a Navegação". A solução por eles encontrada não foi das mais inteligentes, já que facilitava ainda mais o assoreamento, expondo os solos marginais à erosão: "pode o mesmo Tenente Coronel [José da Costa Barreiros], a quem pertencia hûa porção das mesmas margens, ser incumbido de mandar cortar as ditas arvores, quanto baste, para ficar a passagem livre para Barcos grandes" (ANRJ, códice $67, \mathrm{v} .26, \mathrm{fl} .73)$.

Como se aproximava a primavera - quando as árvores produzem matéria orgânica muito mais intensamente e necessitam por isso de mais seiva (ou 'suco vegetante', expressão corrente no Setecentos), o que torna o período pouco adequado para a extração das madeiras - Caetano de Lima e Diogo Ordonhes ordenaram que cessassem os cortes. Havia, além do mais, muita árvore já torada que, à espera do falquejo, ficava exposta às injúrias do tempo’. Para evitar desperdícios, e de acordo com a orientação passada pelo ministro Souza Coutinho, em 1797 ordenaram também que se aproveitassem partes periféricas e menores das perobas, principalmente as raízes:

hé muito precizo, e muito conveniente, não fazer os costumados desperdiços de tão precioza Madeira; que já se vai fazendo rara; e por isso ordenamos igualmente em nome de V.Ex. ${ }^{a}$ ao dito Mestre Agostinho, que aproveitasse em curvas de diversas dimenssoens, as mais grossas e bellas raízes das Parobas, que se elevam horizontalmente sobre a terra, assim como para outras differentes pessas, os restos dos Troncos, e os galhos mais corpulentos, e por qe tudo servia vantajozamente para a Construção Naval, ao menos para a que se faiz no Arsenal desta Cidade, como he notoriamente claro: o que tudo produzirá hua grande quantidade de bellas Madeiras, ainda que de menores construçoens pois que se tem cortado grande numero destas Arvores Colossaes. (ANRJ, códice 67, v.26, fls.73-4)

O corte de Papocaya, por sua vez, ficava nas terras de Antônio de Oliveira Braga. Anteriormente elas haviam pertencido aos jesuítas - donde provinha sua denominação alternativa, 'Fazenda do Colégio'. Localizada, provavelmente, na margem esquerda do Macacu, entre os rios Jaguari e das Pedras, essa grande fazenda constituiu-se apartando-se das terras da antiga aldeia de São Barnabé. Tentaram implantar ali a criação de gado e a policultura, atividades habituais às fazendas jesuíticas. Verificando-se, contudo, com a experiência, que o solo se prestava excepcionalmente bem ao cultivo da mandioca, o lugar especializou-se como fabricante de farinha, chegando a figurar 
como a mais importante fazenda do colégio nesse gênero de produção. Em 1757, empregavam-se nesses trabalhos 223 escravos, 117 bois e 20 cavalos. ${ }^{14}$

As grandes matas dessa fazenda haviam sido deixadas 'quase intactas' pelos padres da Companhia. Isto é confirmado pela distância máxima alcançada entre os locais de extração e o rio $\mathrm{Macacu}$ - onde os toros eram amarrados às extremidades das canoas e levados até a confluência com o Guapiaçu —, 'apenas' uma légua (seis quilômetros), indicando uma fragmentação relativamente pequena do tecido florestal nessa área. É razoável imaginarmos que a grande proximidade do universo indígena conseguida pelos jesuítas, tanto no sentido sociocultural quanto no ecológico-material — isto é, de conhecimento dos usos da natureza local — tenha desempenhado papel decisivo na modelagem de uma atitude mais circunspeta no gerenciamento dos recursos florestais. ${ }^{15}$ Não obstante, talvez mais importante do que isso fosse uma estratégia de 'pousio social' das terras periurbanas: a expansão das lavouras de exportação em direção ao Recôncavo certamente influenciava o cálculo econômico-ambiental dos padres. ${ }^{16}$

Quando da sua expulsão — sacramentada juridicamente pelo marquês de Pombal em 1759 e efetivada no ano seguinte - , a fazenda de Papocaya foi confiscada, passando às mãos da Coroa. Essas terras — como todos os demais bens da dita companhia — foram posteriormente vendidas em hasta pública. É possível que a alienação tenha sido feita já com cláusula referente às prerrogativas régias para o estabelecimento do corte naval ou mesmo com o corte já em funcionamento, embora isso seja pouco provável. Não consegui apurar quando se deu o leilão, nem se o arrematante foi Oliveira Braga. Pode não ter sido este o caso, tendo Oliveira Braga comprado a fazenda posteriormente, inteira ou parcelada. Reforçadores desta última hipótese são os fatos de que a relação do marquês de Lavradio, de 1778, não menciona a graça do dito homem, e o relato de John Luccock, que em 1816 menciona uma outra propriedade que também havia pertencido aos jesuítas, por sua descrição não parece ser a que fora outrora de Oliveira Braga, inclusive pela sua localização. ${ }^{17}$

Certo mesmo é que a lista nominativa anexa à Discripção de 1797 indica que Oliveira Braga possuía 39,6 km² de terras, unidade agrária categorizada no referido documento como 'engenho de açúcar'. Proprietário de um extenso plantel de negros (eram 106 adultos, dos quais 44 homens e 62 mulheres), a produção agrícola de sua propriedade era uma das cinco maiores do distrito: 1.300 arrobas de açúcar, 19 pipas de aguardente, 400 alqueires de farinha, 20 alqueires de feijão, 80 alqueires de arroz e 20 alqueires de milho. Seu rebanho de gado vacum, o maior da região macacuana, compunha-se de 100 bois, 
60 vacas e 20 novilhos; além disso, viviam em seus currais quatro cavalos, 40 bestas e quatro poldros. Desprezando-se a hipótese da precedência jurídica, talvez o grande número de animais de tração de Oliveira Braga - mais do que a riqueza botânica de suas terras - é que tenha influenciado decisivamente na escolha de suas matas para a instalação do corte.

O corte era administrado pelo alferes Antônio de Amorim Lima, maior senhor de engenho da freguesia vizinha de Guapimirim e também possuidor de um porto. Filho mais velho de Domingos de Amorim Lima e Maria da Conceição, Antônio parece ter herdado, provavelmente no começo da década de 1760, a maior e mais bem estabelecida porção da grande propriedade que pertencia a seu pai - aquela na qual se encontrava instalado o moinho onde em 1778 residia com sua irmã solteira. Para sua mãe, o patriarca Domingos deixou o sertão da fazenda, localizado já na freguesia de Santo Antônio de Sá, então fronteira florestal do distrito, onde foi construída nova aparelhagem para o fabrico de açúcar e aguardente. ${ }^{18}$ Seus outros dois irmãos mais novos, José e Francisco (que figuram na lista nominativa de 1797 como lavradores sem terra) provavelmente já estavam estabelecidos em uma das duas propriedades da família como agregados.

Em 1778 Amorim Lima e sua irmã produziram o considerável montante de 30 caixas de açúcar e duas pipas de aguardente, "além de outras colheitas de mantimentos". Contavam, para isso, com 54 escravos e, muito provavelmente, inúmeros lavradores de partido. Há uma cifra concreta para 1797: 12 agregados, que faz de sua propriedade a maior 'acolhedora' de lavradores sem terra do distrito. Passados quase vinte anos, os irmãos continuavam solteiros, embora houvesse duas filhas menores e um filho com mais de 15 anos, prole não se sabe de quem. Suas terras estendiam-se por $8,6 \mathrm{~km}^{2}$. Seu plantel havia diminuído para 45 cativos (38 adultos). A produção agrícola mantinha-se mais ou menos no mesmo nível: 300 arrobas de açúcar, seis pipas de aguardente e 100 alqueires de farinha. A indústria madeireira estava presente na forma de uma dúzia de paus-de-prumo (Discripção..., AHU, Avulsos, Caixa 165 , doc. $\mathrm{n}^{\mathrm{o}} 62$, lista nominativa em anexo).

$\mathrm{O}$ administrador encontrava as mesmas dificuldades verificadas na Posse quanto à cooperação dos fazendeiros quando o assunto era o empréstimo de animais de tração, o que era agravado pelo caráter da economia agrícola do distrito de Santo Antônio de Sá, notadamente marcada pela produção de alimentos para abastecimento interno: 19 "No Destricto de Macacû, onde há poucos Senhores de Engenho, há muitos Lavradores de diversos gêneros, há menos Boys de Carros do que no de Tapacorá” (ANRJ, códice 67, v.26, fl.75). 
Oliveira Braga morreu em 1807, deixando esposa e dois filhos menores (um de três e outro de sete anos). No alegado interesse da prole órfã, a viúva Fermiana Jacinta Coutinho requereu então o inventário do falecido marido, procedimento que nos brindou com um valioso documento para o estudo da presente matéria (ANRJ, Inventários, caixa 867, proc. 2243). Infelizmente, a propriedade fundiária - o item mais importante para o exame aqui proposto - não foi avaliada. A viúva declarou ser senhora de míseras 50 braças (242 $\mathrm{m}^{2}$ ) de terras, que não podiam ser inventariadas em razão de estarem em situação irregular, havendo a necessidade prévia de demarcação e medição do terreno (ANRJ, Inventários, caixa 867, proc. 2243, fl.14).

Apesar de Fermiana ter dado entrada no processo de requisição do inventário em junho de 1807, a avaliação dos bens só foi finalizada quase seis anos depois, em março de 1813. Analisando-a, vê-se que Oliveira Braga havia perdido a maior parte de sua fortuna; não era mais um indivíduo excepcionalmente rico para os parâmetros locais, embora estivesse longe de pertencer à pobreza rural. A soma de todos os seus pertences perfazia 1:148\$910, nada exorbitante no contexto das fortunas cariocas da virada do Setecentos para o Oitocentos. O que mais o aproximava dos primeiros escalões do espectro socioeconômico local eram os metais preciosos (ouro e prata), no valor de $18 \$ 150$. Suas plantações (avaliadas em $323 \$ 200$ ) e, principalmente, o tamanho de sua escravaria, atestavam contra a capacidade produtiva de sua fazenda: possuía apenas seis cativos adultos, e uma das três mulheres do plantel estava "vendida das verilhas, e com hum braço destroncado" (ANRJ, Inventários, caixa 867 , proc. 2243, fls.7-9).

Não tenho condições de explicar a derrocada de Oliveira Braga, nem isso se concatena diretamente com os objetivos deste trabalho. Posso tão-somente aludir com uma hipótese, qual seja, a de que o bom casamento de sua filha tenha custado um generoso dote, enfraquecendo as suas posses (em 1797, a lista nominativa anexa à Discripção acusa a existência de uma filha 'pequena', isto é, com menos de 12 anos de idade; dez anos mais tarde, ela provavelmente já teria se casado e deixado a casa dos pais). O importante para a presente investigação é que o retalhamento da terra certamente diminuiria a área de mata e dificultaria o corte das madeiras navais, que deve ter sido interrompido entre 1807 e 1808. A interrupção de um dos mais importantes cortes da capitania pode ter se refletido na drástica redução da produção fluminense para exportação para níveis consideravelmente menores até o ano de 1814, quando volta ao patamar anterior. ${ }^{20}$

O administrador Amorim Lima sobrepunha-se a um pequeno número 
de 'fabricantes', agricultores possuidores de terras próprias e produtores de peças de madeira falquejada para o suprimento da ribeira. Um caminho possível para a identificação desses atores é verificar, na lista nominativa anexa à Discripção, quem produzia 'curvas', já que, dos oito tipos de peças arroladas (tábuas, cossoeiras, vigas, frechais, paus-de-prumo, pernas-de-asna, caibros, e curvas), esta é a única que se aplica exclusivamente à construção naval. É claro que tábuas e cossoeiras também eram usadas na construção naval, mas a amplitude de seu emprego torna perigosa sua utilização como indicador de vinculação ao arsenal real.

A produção de curvas era muito pequena se comparada à produção madeireira total. Das 1.489 dúzias de peças fabricadas no ano de 1797, apenas 15 eram de curvas - isto é, pouco mais de $1 \%$ - mais numerosas apenas que os caibros. Este montante fora produzido por quatro unidades agrárias, cujos donos eram João da Costa Cardoso, o alferes José dos Santos Lobo, o alferes Francisco José e Martinho Lourenço.

João da Costa Cardoso era um dos 27 senhores de engenho de Santo Antônio de Sá e produtor da maior quantidade de curvas - única qualidade de peça de madeira por ele produzida —, em 1797 (sete dúzias, quase metade da produção total). Dono de apenas $2,2 \mathrm{~km}^{2}$ de terras (muito pouco para um engenho açucareiro), casado, porém sem filhos, Costa Cardoso possuía um plantel de 21 escravos, além de ter um agregado em sua propriedade. Ao lado das 300 arrobas de açúcar e das seis pipas de aguardente, produzia quase todos os gêneros alimentícios (farinha de mandioca, feijão e arroz).

O alferes José dos Santos Lobo era o maior cortador de madeira da bacia do Macacu. Em 1797 sua produção foi de 80 dúzias de peças — cifra atingida por apenas mais dois produtores. Além das quatro dúzias de curvas, fabricava tábuas, vigas, frechais e paus-de-prumo. Suas terras estendiam-se por vastíssimos $150 \mathrm{~km}^{2}$. Era casado e pai de um filho 'maior'. Possuía um plantel respeitável de 48 escravos e abrigava quatro agregados em sua propriedade. Quanto à produção agrícola, suas terras caracterizavam-se como uma típica unidade de abastecimento alimentar interno: em 1797, moeu 300 alqueires de farinha e colheu 12 alqueires de feijão, 180 alqueires de arroz e 12 alqueires de milho.

Martinho Lourenço era um lavrador solteiro e dono de míseros cinco escravos. O tamanho de suas terras, contudo, era superior ao das propriedades de alguns senhores de engenho: $5 \mathrm{~km}^{2}$. Além das três dúzias de curvas, em 1797 produziu 60 alqueires de farinha (moídos em fábricas alheias) e 20 alqueires de arroz. 
O alferes Francisco José, casado e pai de dois filhos 'maiores', possuía 22,5 $\mathrm{km}^{2}$ de terras. Sua escravaria contava parcos 10 indivíduos. Assim como seu colega de patente Santos Lobo, engajava-se numa produção de gêneros de primeira necessidade: em 1797 moeu 100 alqueires de farinha de mandioca e colheu cinco alqueires de feijão, 50 alqueires de arroz e 15 alqueires de milho.

É importante notar que nenhuma dessas produções madeireiras constituía, em si mesma, um corte naval; esses indivíduos eram fabricantes de madeira, fornecedores 'contratados' pelo administrador Amorim Lima. A inferência é corroborada pelo fato de que a Antonio de Oliveira Braga, em cujas terras estava instalado o corte de Papocaya, não se rubrica nenhuma produção de madeira.

Tais agentes — os que mais apropriadamente poderíamos chamar de 'madeireiros' - , alguns deles donos de toscas serrarias hidráulicas, muitas vezes compravam madeira em tora de habitantes mais pobres (índios e caboclos) ou os empregavam como jornaleiros nas lavras florestais. Tudo leva a crer que sejam esses trabalhadores jornaleiros os 55 indivíduos relacionados sob a denominação de 'serradores' na lista nominativa da Discripção: nenhum deles possuía terras e a maioria nada plantava. Alguns não tinham nenhum bem, como Manoel Moreira, Ângelo de Souza e Antonio Francisco Ferreira, todos solteiros; João Rodrigues e Francisco Lopes Cardoso estavam na mesma situação, com a diferença de que eram casados - embora não tivessem filhos pequenos para alimentar, o que lhes atenuava a penúria. Uma prole de idade mais avançada (acima de 15 anos), porém, significava indivíduos potencialmente produtivos, que certamente auxiliavam o pai nos matejos e falquejos, especialmente quando a família não praticava nenhum tipo de agricultura, como era o caso de Joaquim José da Costa e sua esposa.

Outros serradores, embora também não cultivassem a terra, tinham algumas parcas posses, como um cavalo ou, mais raramente, uma ou duas cabeças de gado vacum. Seis deles possuíam escravos: eram plantéis unitários, com exceção daquele de Alexandre Cardoso, que era dono de um par composto de mãe e filho.

Uma minoria conseguia tirar da terra alguns alqueires de mantimentos. O produto mais comum era a farinha de mandioca, via de regra moída em tipitis de outrem. Os rendimentos variavam de 10 a 240 alqueires. Pouquíssimos logravam uma diversificação agrícola que ultrapassasse dois gêneros. Gaspar Sardinha e José Ferreira estavam entre esses privilegiados: o primeiro produzia 50 alqueires de farinha, oito de feijão, 30 de arroz e 12 de milho; já o segundo colhia 60 alqueires de farinha, 12 de feijão e 40 de milho. 
Esses homens e mulheres decerto faziam parte do que Miller definiu como a "grande população mista de subsistência" (large mixed subsistence population) dessas áreas que se acostumou chamar de 'boca de sertão': índios, negros libertos, mulatos, pardos e brancos pobres que "estavam disponíveis para empregar sua habilidade de corte num mercado de trabalho livre" (Miller, 2000, p.107). "Muitos [habitantes] ... não se empregam na [agri]cultura, e vivem inclinados ao ofício de mateiros, e é regra quase geral em todos os que não têm escravos; porque se lhe faz difícil a lavoura, por não poder uma só pessoa colher e desmanchar..." (Discripção..., AHU, Avulsos, Caixa 165, doc. no 62 , cap.10).

A julgar pelo sentido atual do termo, os mateiros seriam os indivíduos que fazem a prospecção da mata, observando o tamanho e a espécie das árvores que a compõem, à procura das essências com valor comercial. Não há, entretanto, meios para determinar o significado mais comum da palavra, o mais provável é que fosse polissêmica. Algumas vezes era usada para aludir a uma ou outra função específica como a acima referida, outras, a todo o conjunto de ofícios associados à atividade madeireira, indistintamente. Caetano de Lima fala, por exemplo, em "Mateiros que costumão fazer Madeiras" (ANRJ, caixa 498 , pct. $01, \mathrm{n}^{2} 2$ ), uma clara indicação de que o termo podia ser aplicado a falquejadores e serradores.

A lista nominativa mostra também a presença de alguns carpinteiros. Não me foi possível determinar se esses oficiais mecânicos eram empregados nos cortes das madeiras navais, embora isso seja plausível. Os engenhos açucareiros tinham extrema necessidade do trabalho desses profissionais especializados, que podiam ser tanto escravos como homens livres assalariados. Em sendo cativos, eram usurpados; em se tratando de trabalhadores livres e excluindo, obviamente, a hipótese de coerção —, fazia-se mais difícil o caso, em razão da muito difundida fama de má pagadora da Coroa. Inquestionavelmente, a prática de ceder mestres-carpinteiros aos administradores dos cortes - como fazia João Coutinho Pereira, o 'vassalo-modelo' sobre o qual já se comentou mais atrás - constituía exceção, o que significava pagar o dito oficial para que laborasse para a Coroa.

\section{CONSIDERAÇÕES FINAIS}

A navegação marítima (transoceânica e de cabotagem) e fluvial desempenhou, desde o começo, papel de relevo singular na formação histórica do 
Brasil. A construção naval era uma genuína 'empresa de base', conforme classificou Lapa, estimulando um razoável número de atividades ancilares, requisitando e concentrando considerável mão-de-obra - tanto braçal como qualificada - e mobilizando grandes quantidades de recursos naturais. ${ }^{21} \mathrm{O}$ principal deles era a madeira.

Diferentemente dos 'produtos de conjuntura', que circunscreveram seus espaços e definiram contornos regionais na história brasileira, a madeira, pertencente a uma realidade mais elementar, passava despercebida pelos homens e mulheres que dela faziam uso cotidianamente, o que se reflete, claramente, na maneira fragmentada como ela aparece nos registros escritos da época e conseqüentemente nas descrições historiográficas. Doravante, resgatar essa importante feição da estrutura da economia colonial é um desafio que se impõe, preponderantemente aos historiadores ambientais. Em termos ecológicos, uma sociedade pré-industrial 'voltada para o mar' significa uma sociedade 'voltada para as florestas'. O navio de madeira foi a mais elevada expressão da cultura material do período moderno bem como a grande ferramenta de expansão, dominação e comercialização dos europeus. São os navios de madeira que, pelos fins do medievo, lançam os portugueses à epopéia das conquistas ultramarinas, fincando as bases da formação do que viria a ser o primeiro grande império colonial moderno.

Nas últimas três décadas de domínio luso, num contexto de decadência imperial e crise financeira pós-ciclo da mineração, tenta-se arrochar o pacto colonial. Isto se expressou, no plano da política florestal, pela (tentativa de) monopolização régia de todas as matas à borda do mar e de todos os rios navegáveis (1797). Tal movimento estava intimamente ligado a uma tentativa de 'modernização' ilustrada do aparato estatal português, no centro do qual ainda figurava o ideário mercantilista. Neste sentido, a recuperação da frota mercante e de guerra, destroçada e abandonada desde fins do século XVII, era uma tarefa crucial. Nada mais natural, então, do que um esforço para reavivar um antigo pólo de construção naval da colônia — o Rio de Janeiro ainda mais naquele momento, em que ele havia se tornado capital do vicereinado. Contudo, as restrições orçamentárias, a conjuntura externa desfavorável, o parco conhecimento das potencialidades econômicas da flora fluminense e as ineficiências organizativas não permitiram que o projeto fosse bem-sucedido. 


\section{NOTAS}

${ }^{1}$ Este trabalho resulta de uma pesquisa financiada pela Capes. O autor agradece as contribuições de José Augusto Pádua e Maurício de Almeida Abreu, orientadores da dissertação de mestrado (PPGHIS/UFRJ) cujo segundo capítulo constitui, com algumas alterações, o cerne do presente texto. As referências às fontes primárias encontram-se no corpo do texto e seguem as seguintes abreviações: AHU — Arquivo Histórico Ultramarino (Lisboa), ANRJ - Arquivo Nacional do Rio de Janeiro.

${ }^{2}$ Interessante é notar a durabilidade dessa representação que identificava as madeiras aos seus respectivos territórios coloniais de ocorrência, encontrada até meados do século passado em tratados de botânica econômica. Ver, por exemplo, SEABRA, Luiz de; FERREIRINHA, Manuel P. Madeiras coloniais. Lisboa: Min. das Colónias, Junta de Investigações Coloniais, 1950; BOND, C. W. Colonial timbers. London: Sir Isaac Pitman \& Sons, 1950.

${ }^{3}$ MARQUES, J. M. da Silva. Descobrimentos portugueses. v.1. Lisboa, 1944, p.7.

${ }^{4}$ LISBOA, Balthazar da Silva. Anais do Rio de Janeiro. tomo I. Rio de Janeiro: Ed. Leitura, 1967 [1834-5], p.401.

${ }^{5}$ LAPA, José Roberto do Amaral. A Bahia e a carreira da Índia. São Paulo: Cia. Ed. Nacional, 1968, p.38; MORTON, F. W. O. The royal timber in late colonial Bahia. Hispanic American Historical Review, v.58, 1978, p.41-61; MILLER, Shawn William. Fruitless trees: Portuguese conservation and Brazil's colonial timber. Stanford: Stanford University Press, 2000.

${ }^{6}$ DEAN, Warren. A ferro e fogo: a história e a destruição da Mata Atlântica brasileira. São Paulo: Companhia das Letras, 1996, p.153.

${ }^{7}$ LISBOA, 1967, p.400-1; LAVRADIO, Marquês de. Relação — parte II. Revista do Instituto Histórico e Geográfico Brasileiro, v.76, 1946 [1779], p.333.

${ }^{8}$ CASAL, Manuel Aires de. Corografia brasílica. São Paulo: Ed. Cultura, 1943, p.78.

${ }^{9}$ BROWN, Larissa V. Urban growth, economic expansion, and deforestation in late colonial Rio de Janeiro. In: STEEN, H. K.; TUCKER, R. P. (Ed.) Changing tropical forests: historical perspectives on today's challenges in Central and South America. Durham (NC): Forest History Society, 1992, p.167.

${ }^{10}$ ALENCASTRO, Luiz Felipe de. O trato dos viventes: formação do Brasil no Atlântico Sul, séculos XVI e XVII. São Paulo: Companhia das Letras, 2000, p.197; ALMEIDA, Maria Regina C. Metamorfoses indígenas: identidades e cultura nas aldeias coloniais do Rio de Janeiro. Rio de Janeiro: Arquivo Nacional, 2003, p.202; MONTEIRO, John M. Entre o etnocídio e a etnogênese: identidades indígenas coloniais. In: FAUSTO, C.; MONTEIRO, J. M. (Org.) Tempos índios: histórias e narrativas do Novo Mundo. Lisboa: Assírio e Alvim, no prelo.

${ }^{11} \mathrm{O}$ autor desse documento, contudo, não identifica, dentre os empregos produtivos des- 
sas gentes, o extrativismo madeireiro; cita-se, porém, a lavoura, a pescaria e o artesanato (balaios, esteiras e outros instrumentos de palha, bem como taquaras).

${ }^{i 2}$ CAVALCANTI, Nireu. O Rio de Janeiro setecentista: a vida e a construção da cidade da invasão francesa até a chegada da corte. Rio de Janeiro: Jorge Zahar, 2003. p.113.

${ }^{13}$ Este dado parece estar de acordo com o padrão dos cortes de madeiras navais de fins do Setecentos: se em áreas de ocupação antiga, como Iguape (capitania de São Paulo), não havia mais árvores apropriadas num raio de 60 quilômetros da barra, em outras, de ocupação mais recente - mormente áreas que se abriam como fronteira agrícola —, como o distrito fluminense de Campos dos Goitacazes, as toras tinham de ser arrastadas de três a nove quilômetros até a costa. Cf. DEAN, 1996, p.152.

${ }^{14}$ SERAFIM LEITE, S. I. História da Companhia de Jesus no Brasil. Tomo VI. Rio de Janeiro: Instituto Nacional do Livro, 1945, p.114.

${ }^{15}$ Isto não quer dizer que não houvesse, por parte dos jesuítas, um esforço particular no sentido de desenvolver a exploração madeireira. Serradores, carpinteiros, entalhadores, embutidores, marceneiros, tanoeiros e torneiros eram ofícios regularmente exercidos entre os padres e irmãos, que também os ensinavam os nativos que catequizavam. Cf. SERAFIM LEITE, S. I. Artes e ofícios dos jesuítas no Brasil (1549-1760). Lisboa: Edições Brotéria, 1956, p.23-26, 44-47.

${ }^{16}$ FERREIRA, João da Costa. A cidade do Rio de Janeiro e seu termo: ensaio urbanológico. Rio de Janeiro: Imprensa Nacional, 1933, p.129-130.

${ }^{17}$ LUCCOCK, John. Notas sobre o Rio de Janeiro e partes meridionais do Brasil. Belo Horizonte: Itatiaia, 1975, p.232.

${ }^{18}$ Isto depreendo dos precários dados fornecidos por LAVRADIO, 1946, p.290-1.

${ }^{19}$ SILVA, Francisco Carlos Teixeira da. A morfologia da escassez: crises de subsistência e política econômica no Brasil Colônia (Salvador e Rio de Janeiro, 1680-1790). Niterói, 1989. Tese (Doutorado em História) -Instituto de Ciências Humanas e Filosofia, Universidade Federal Fluminense, p.166-167, 172; ABREU, Maurício de Almeida. Processo de conquista e apropriação do território: Capitania do Rio de Janeiro, 1564-1600. Anais do VI Encontro da ANPUR. Belo Horizonte, 2003 (CD-rom).

${ }^{20}$ MILLER, 2000, p.73. Sem dúvida teve parte nisso a chegada da família real ao Rio, desorganizando sensivelmente os trâmites prévios da administração colonial.

${ }^{21}$ LAPA, José Roberto do Amaral. História de um navio (Bahia, 1755-1788). In: Economia colonial. São Paulo: Perspectiva, 1973, p.238.

Artigo recebido em novembro de 2007. Aprovado em abril de 2008. 